\title{
Estimation of the Poisson's Rate of the Intact Rock in the Function of the Rigidity
}

\author{
Benedek A. Lógó1* ${ }^{\star}$ Balázs Vásárhelyi ${ }^{1}$ \\ 1 Department of Engineering Geology and Geotechnics, Faculty of Civil Engineering, Budapest University of Technology and \\ Economics, H-1521 Budapest, P.O.B. 91, Hungary \\ * Corresponding author, e-mail: logo.benedek@epito.bme.hu
}

Received: 07 September 2019, Accepted: 24 September 2019, Published online: 14 October 2019

\begin{abstract}
Although Poisson's ratio is one of the basic rock mechanical parameters, it is less investigated than the other parameters. It can be assumed, that this material constant depends on the rigidity of the rock, among the others. The goal of this research is to find a theoretical relationship between the rigidity of the intact rock and Poisson's ratio. It was assumed that there is a connection between the internal friction angle (or cohesion) and rigidity of the isotropic, linear elastic material, using the Mohr-Coulomb theory. Based on these equations from different published limit equilibrium, six different equations were compared. It is published that the rigidity value is equal (within the experimental error) to the Hoek-Brown material constant $\left(m_{\mathrm{i}}\right)$ which value is well-known for many different rock types. Plotting the published Poisson's ratio in the function of the rigidity of the intact rock the optimal connection was chosen.
\end{abstract}

\section{Keywords}

rock mechanics, internal friction angle, Poisson's rate value, rigidity, Hoek-Brown constant

\section{Introduction}

The knowledge of the Poisson's rate value is important during the rock engineering process. It can be measured from classical uniaxial compressive strength tests, according to the ISRM suggestion [1]. The definition of Poisson's ratio can be stated as the ratio of transverse strain to axial strain induced by unconfined axial deformation. Theory of elasticity gives limiting range of Poisson's ratio as:

$-1 \leq v \leq 0.5$.

Also note that, strictly, there is a sign with $v$, so that $(+)$ means an elongation strain with lateral contraction and a compression strain with lateral expansion. No rock is known that might give a (-) ratio where there is lateral expansion with elongation or lateral contraction with compression. It means, that the Poisson ratio of the rock materials usually:

$$
0.1 \leq v \leq 0.4
$$

Firstly, Kumar [2] investigated the effect of the Poisson's ratio on the intact rock properties. He showed the importance of this material constant in the rock mechanics. According to his results, there is linear relationship between the Young's modulus $(E)$, uniaxial compressive strength $\left(s_{\mathrm{c}}\right)$, tensile strength $\left(s_{\mathrm{t}}\right)$ and the Poisson's ratio $(v)$ :
- $E$ increases with decreasing Poisson's ratio [2];

- Compressive strength increases with increasing Poisson's ratio [2];

- Tensile strength decreases with increasing Poisson's ratio [2].

Aydan et al. [3] carried out several laboratory tests of squeezing rocks in Japan. It was assumed that the Poisson's ratio of rocks trends to approach 0.5 as the uniaxial strength approach to zero and as the strength increases it tends to converge a value between 0.2 and 0.25 . The relation between Poisson's ratio $(v)$ and uniaxial strength $\left(s_{\mathrm{c}}\right.$ in $\mathrm{MPa})$ is the following for squeezing rocks [3]:

$$
v=0.25\left(1+e^{-0.2 \sigma_{\mathrm{c}}}\right) \text {. }
$$

Analyzing the porosity and the density he found, that small change in Poisson's ratio there is a big change in porosity and there is a linear relationship between the density and the Poisson's ratio. Gercek [4] compared to other basic mechanical properties of rocks, Poisson's ratio is an elastic constant of which the significance is generally underrated. There are a considerable number of diverse areas, in rock mechanics which require a 
prior knowledge or estimation of the value of Poisson's ratio. His paper examined the values and applications of Poisson's ratio in rock mechanics. Following a historical account of the initial controversy, whether it was a material constant or not, the effects of Poisson's ratio in the elastic deformation of materials, intact rocks, and rock masses are briefly reviewed. Also, the reported values of Poisson's ratio for some elements, materials, and minerals are compiled while typical ranges of values are presented for some rocks and granular soils.

In addition to it Poisson's ratio classifications are recommended for isotropic intact rocks. Note, according to the results of Davarpanah et al. [5], the Poisson's ratio highly depend on the stress, as well. Testing of Westerly granite by Walsh [6] showed that Poisson's ratio is not constant but continuously increases throughout loading, varying from 0.2 to 0.3 between 30 and $60 \%$ peak strength where elastic behavior is typically assumed. This uncertainty can result in CI values that differ by up to $\pm 40 \%$ for a change of \pm 0.05 in the Poisson's ratio assumed [6].

Unfortunately, in many cases it is not possible to determine the Poisson's ratio of the intact rock. Typical ranges of values for Poisson's ratio of some rock types were collected by Gercek [4] presented in Fig. 1 and the suggestion of American Association of State Highway and Transportation Office [7] in Table 1.

It can be assumed, that the Poisson's ratio depend on the rigidity of the intact rock - increasing the brittleness of the rock material the Poison's ratio should be decreasing. Vásárhelyi [8] assumed a linear relationship between the Hoek-Brown material constant $\left(m_{\mathrm{i}}\right)$ and the Poisson's ratio:

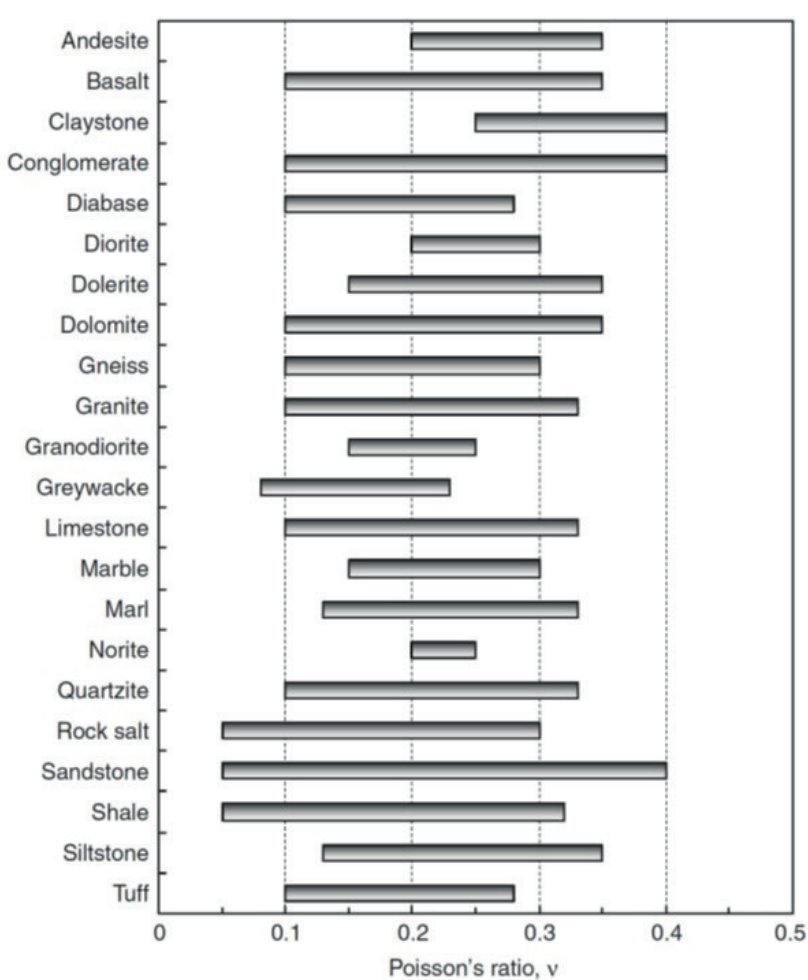

Fig. 1 Typical ranges of values for Poisson's ratio of some rock types (collected by Gercek [4])

increasing the Hoek-Brown constant $\left(m_{\mathrm{i}}\right)$ the Poisson's ratio linearly decreases:

$v=0.257-0.003 m_{\mathrm{i}}$.

Recently, Kumar et al. [9] investigated the influence of the unconfined compressive strength to the Poisson's rate. Analyzing six different rock types (such as: basalt, granite, schist, limestone, sandstone and shale) they received, that

Table 1 Typical values of Poisson's ratio of intact rocks (after [7])

\begin{tabular}{lccccc}
\hline \multirow{2}{*}{ Rock type } & No. of values & \multicolumn{3}{c}{ Poisson's ratio } & $\begin{array}{c}\text { Standard } \\
\text { deviation }\end{array}$ \\
\cline { 3 - 5 } Granite & 22 & maximum & minimum & Mean & 0.08 \\
Gabbro & 3 & 0.30 & 0.09 & 0.20 & 0.02 \\
Diabase & 6 & 0.20 & 0.16 & 0.18 & 0.06 \\
Basalt & 11 & 0.38 & 0.20 & 0.29 & 0.05 \\
Quartzite & 6 & 0.32 & 0.16 & 0.23 & 0.05 \\
Marble & 5 & 0.22 & 0.08 & 0.14 & 0.08 \\
Gneiss & 11 & 0.40 & 0.17 & 0.28 & 0.09 \\
Schist & 12 & 0.40 & 0.09 & 0.22 & 0.08 \\
Sandstone & 12 & 0.31 & 0.02 & 0.12 & 0.11 \\
Siltstone & 3 & 0.46 & 0.08 & 0.20 & 0.06 \\
Shale & 3 & 0.23 & 0.09 & 0.18 & 0.06 \\
Limestone & 19 & 0.18 & 0.03 & 0.09 & 0.06 \\
Dolostone & 5 & 0.33 & 0.12 & 0.23 & 0.08 \\
\hline
\end{tabular}


the Poisson's rate linearly increasing in case of increasing uniaxial compressive strength (UCS). These published results are summarized in Table 2.

\section{Theoretical background}

Using the Mohr-Coulomb theory (Fig. 2), the internal friction angle $(\varphi)$ in the function of the rigidity $(R)$ can be determined. According to Andreev [10] there are several definitions for calculating the rigidity $(R)$ of the rock material. In this paper it was suggested to determine it in the ratio of the uniaxial compressive strength $\left(s_{\mathrm{c}}\right)$ and the tensile strength $\left(s_{\mathrm{t}}\right)$ of the rock material, i.e.:

$$
R=\frac{\sigma_{\mathrm{c}}}{\left|\sigma_{\mathrm{t}}\right|}
$$

Knowing this ratio, using the Mohr-Coulomb theory, the internal friction angle $(\varphi)$ can be determined using the following equation:

$\phi=\arcsin \frac{R-1}{R+1}$.

The internal friction angle $(\varphi)$ in the function of rigidity $(R)$ is plotted in Fig. 3.

Similarly, a lower bound estimate of cohesion (c) for rock would be obtained most simply by assuming a straight-line, rather than a curved tangent between the uniaxial tension $\left(\sigma_{\mathrm{t}}\right)$ and uniaxial compression $\left(\sigma_{\mathrm{c}}\right)$ Mohr circles (see Fig. 2). The simple equation for the lower bound cohesion intercept (c), derived from Mohr circle geometry, was given in Barton [11]:

$c=\frac{1}{2}\left(\sigma_{\mathrm{c}} \cdot \sigma_{\mathrm{t}}\right)^{\frac{1}{2}}$.

According to Cai [12], when the rigidity of the intact rock $R \geq 8$, the error for approximating the Hoek-Brown constant $m_{\mathrm{i}}[13,14]$ is less than $1.6 \%$ (see Fig. 4). It means that the Hoek-Brown constant can be calculated from the ratio of the uniaxial compressive strength $\left(s_{\mathrm{c}}\right)$ and tensile strength $\left(s_{\mathrm{t}}\right)$.

Table 2 Summary of Poisson's ratio $(v)$ and UCS relationships $(f)$ [9].

\begin{tabular}{lcc}
\hline Rock & $\begin{array}{c}v \text { and UCS relationship } \\
{[\text { UCS }(\mathrm{MPa})]}\end{array}$ & $f_{\mathrm{c}}$ range \\
\hline Basalt & $v=0.235+0.0002 f_{\mathrm{c}}$ & $170-415$ \\
Granite & $v=0.246+0.0002 f_{\mathrm{c}}$ & $70-276$ \\
Schist & $v=0.16+0.00057 f_{\mathrm{c}}$ & $35-105$ \\
Limestone & $v=0.186+0.0016 f_{\mathrm{c}}$ & $35-170$ \\
Sandstone & $v=0.136+0.00227 f_{\mathrm{c}}$ & $28-138$ \\
Shale & $v=0.208+0.00606 f_{\mathrm{c}}$ & $7-40$ \\
\hline
\end{tabular}

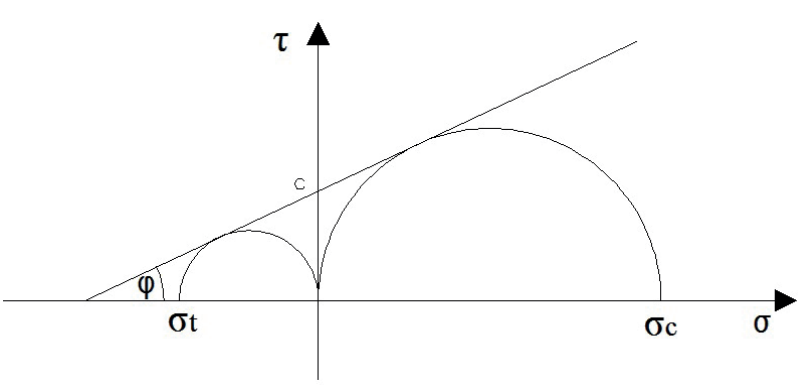

Fig. 2 The theoretical figure of the Mohr-Coulomb failure criterion with the $\varphi$ and $\mathrm{c}$ value

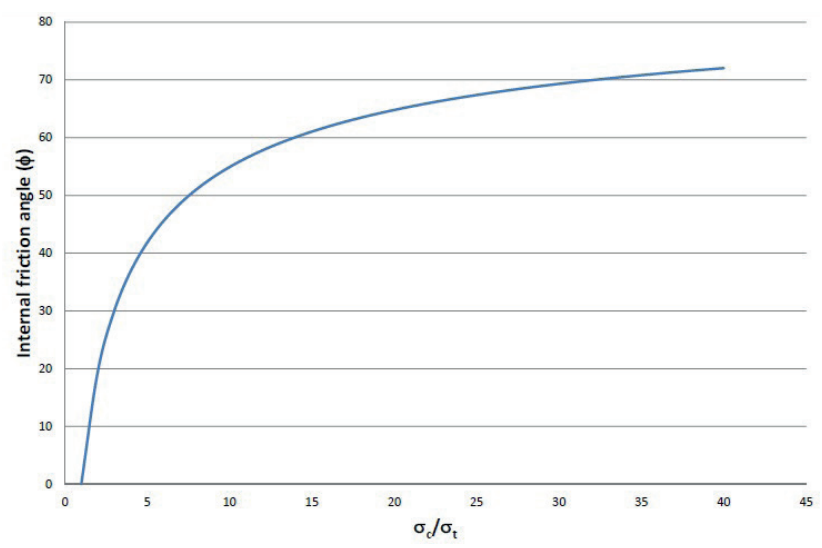

Fig. 3 The internal friction angle in the function of the rigidity of the rock material according to the Mohr-Coulomb theory

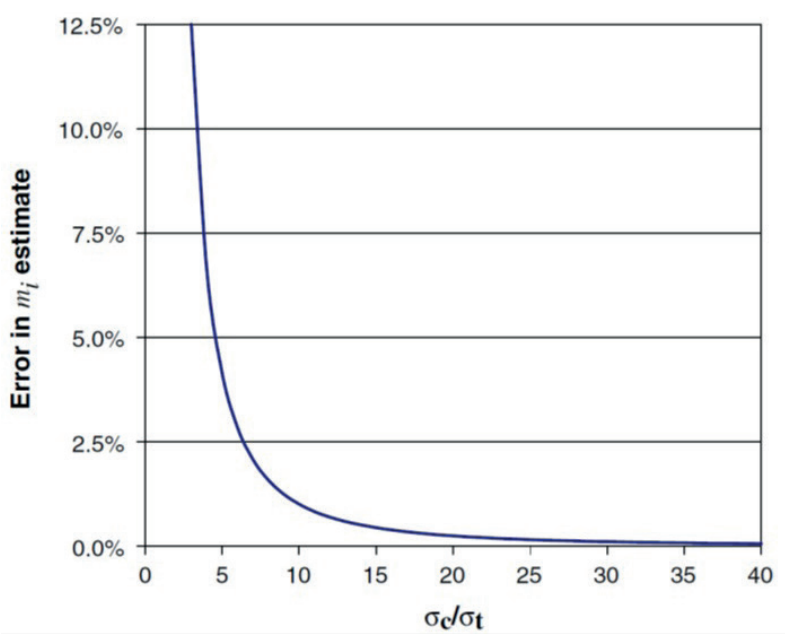

Fig. 4 Relationship between error in $m_{\mathrm{i}}$ (Hoek-Brown material constant) estimate and the strength ratio $R$, according to Cai [12]

The Hoek-Brown constants $\left(m_{\mathrm{i}}\right)$ of the intact, isotropic rocks are usually well-known. These values of the most important rock types were collected in Table 3 (using the published data of Hoek [15]. According to Table 3, the minimal value of $m_{\mathrm{i}}$ is 2 (e.g. claystone) and the maximum value is 35 for some granitic rocks. 


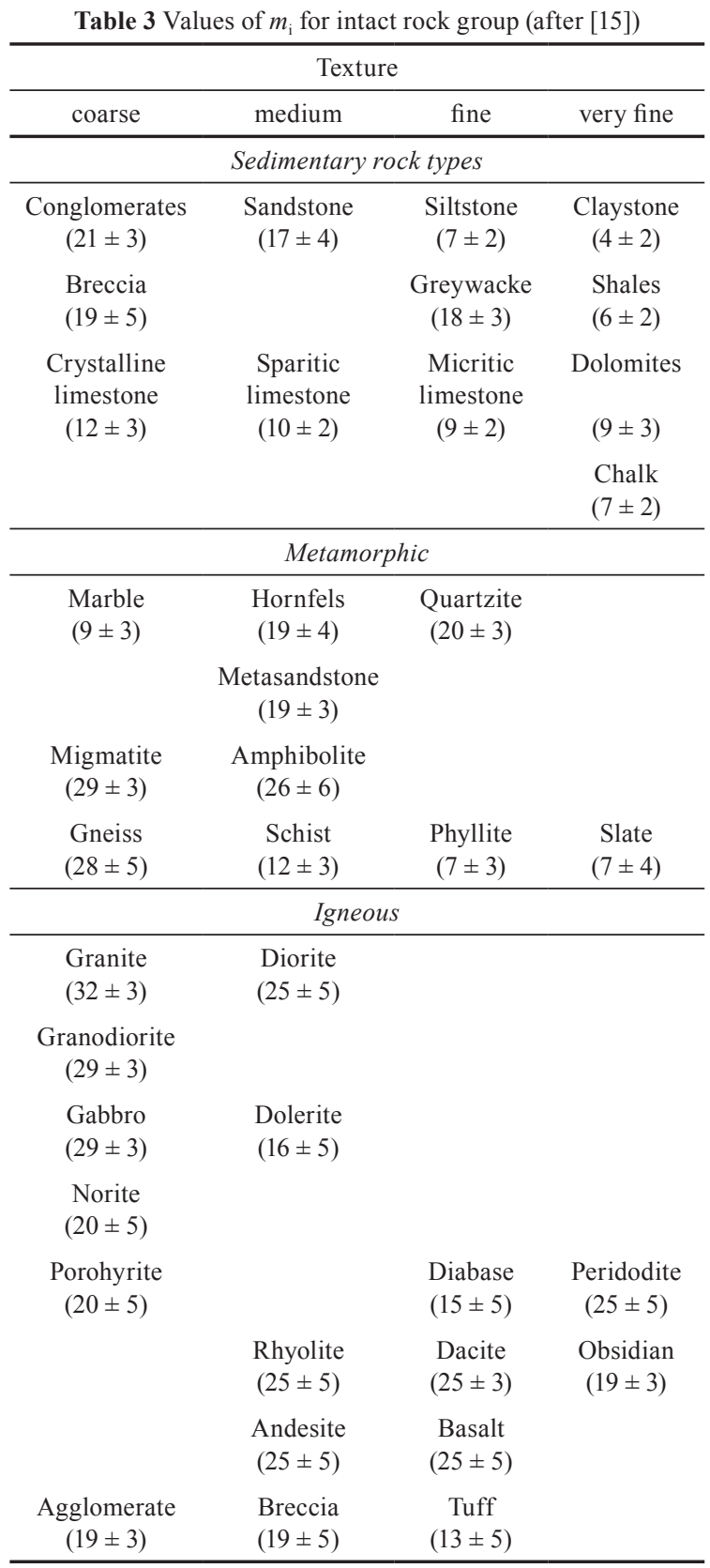

3 Relationships between rigidity and Poisson's rate value Zhang et al. [16] summarized the most important relationships between the internal friction angle $(\varphi)$ and the Poisson's rate $(v)$ of the intact solid material. All of these equations based on Mohr-Coulomb theory, and they used the different equilibrium methods by Stagg and Zienkiewicz [17]. The following correlations were collected by $[16]$ :

$v=\frac{1}{2}(1-\sin \phi)$

$v=\frac{\cos ^{2} \phi}{1+\cos ^{2} \phi}$

$$
\begin{aligned}
& v=\frac{\arctan [\cos \phi-(1-\sin \phi) \tan \phi]}{90^{\circ}} \\
& v=\frac{1-\sin \phi}{2+\sin \phi} \\
& v=\frac{\tan \left(45^{\circ}-\frac{\phi}{2}\right)}{1+\tan \left(45^{\circ}-\frac{\phi}{2}\right)} .
\end{aligned}
$$

Replacing the $\varphi$ value in Eq. (6), these relationships can be rewritten to the following form, which are independent to the internal friction angle $(\varphi)$ - i.e. depend on only the rigidity $(R)$ of the intact rock (note: as it was mentioned earlier, the $R$ is in most cases equal to the $m_{\mathrm{i}}$ Hoek-Brown material constant):

$$
\begin{aligned}
& v=\frac{1}{R+1} \\
& v=\frac{4 R}{R^{2}+6 R+1} \\
& v=\arcsin \left[\frac{\left.(R+1) \cdot \sqrt{\frac{R+1}{R}} \cdot \sqrt{\frac{R}{(R+1)^{2}}}\right]}{v=\frac{2}{3 R+1}}\right. \\
& v=\frac{1}{\sqrt{R}+1} .
\end{aligned}
$$

According to the published collection of [16], the Poisson's rate can be calculated from the cohesion (c) and the uniaxial compression $\left(s_{\mathrm{c}}\right)$ of the intact rock material, as well, i.e.:

$$
v=\frac{\mathrm{c}}{\sigma \mathrm{c}}
$$

or

$v=\frac{2 \mathrm{c}}{\sigma \mathrm{c}+2 \mathrm{c}}$.

Using Eq. (7), the following form can be used the following form (which are independent on the strength and the cohesion of the rock, i.e. depend on only the rigidity)

$v=\frac{1}{2 \sqrt{R}}$

or 
$v=\frac{1}{\sqrt{R}+1}$

\section{Results and discussion}

The above presented methods (Eqs. (8)-(14)) were plotted in Fig. 5, which illustrates that when using these equations, Poisson's ratio decreases as rigidity increases. This non-linear behavior also indicates higher sensitivity until $R \approx 10$. In case of brittle rocks $(R>10)$ the influence of the rigidity is not so significant. Based on these relationships, Poisson's ratio is equal to 0.5 in case of $R=1$ (i.e. plastic material). Reaching the maximum rigidity of the rock (i.e. $R=35$ ) the minimum Poisson's rate is between 0.02 (using Eq. (10)) and 0.14 (Eq. (12) and (14)). According to the published data the lowest Poisson's rate is around 0.1.

In Fig. 6, the minimum and maximum Poisson's ratio values $(v)$ are plotted in the function of the Hoek-Brown constant $\left(m_{\mathrm{i}}\right)$ of the rock (according to Table 3, applying the average values), using the both results of Gercek [4] from Fig. 2 and the suggestion of AASHTO [7] (Table 1). There are only two points out of the line: the shale and siltstone from the list of AASHTO [7]. Note, the Hoek-Brown constant of these types of rock are usually very sensitive.

These applied data (minimum, maximum values of the Poisson's rate (v) and the Hoek-Brown material constant $\left.m_{\mathrm{i}}\right)$ are summarized in Table 4.

Comparing the different relationships Eq. (12), (14) is the best fit curve. It means, Eq. (15) is assumed between the relationship of the rigidity and the Poisson's rate value, depending on the ratio of the uniaxial compressive strength $\left(\sigma_{\mathrm{c}}\right)$ and tensile strength $\left(\sigma_{\mathrm{t}}\right)$ :

$v=\frac{1}{\sqrt{\frac{\sigma_{c}}{\left|\sigma_{t}\right|}}+1}$.

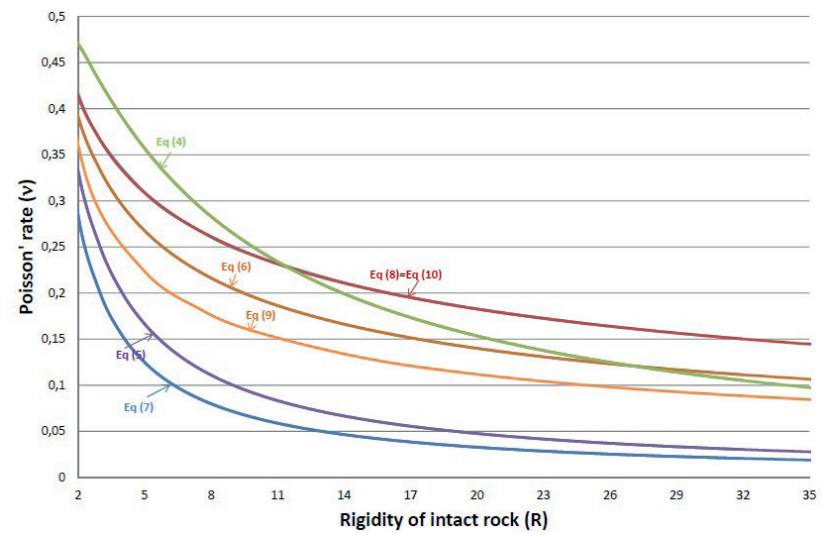

Fig. 5 Prediction of the Poisson's ratio in the function of the rigidity of the intact rock - equations according to [16]
Table 4 Summarized the applied values of different rock types: average Hoek-Brown constant, minimum and maximum Poisson's rate values

(1): Gercek [4]; (2): AASHTO [7]

\begin{tabular}{|c|c|c|c|}
\hline \multirow{2}{*}{ Type of the rock } & \multirow{2}{*}{$\begin{array}{c}\text { Hoek-Brown } \\
\text { constant }\end{array}$} & \multicolumn{2}{|c|}{ Poisson's rate value $(v)$} \\
\hline & & $\min$ & $\max$ \\
\hline Andesite (1) & 25 & 0.20 & 0.35 \\
\hline Basalt (1) & 25 & 0.10 & 0.35 \\
\hline Basalt (2) & 25 & 0.16 & 0.32 \\
\hline Claystone (1) & 4 & 0.25 & 0.40 \\
\hline Conglomerate (1) & 21 & 0.10 & 0,40 \\
\hline Diabase (1) & 15 & 0.10 & 0.28 \\
\hline Diabase (2) & 15 & 0.20 & 0.38 \\
\hline Diorite (1) & 25 & 0.20 & 0.30 \\
\hline Dolerite (1) & 16 & 0.15 & 0.35 \\
\hline Dolomite (1) & 9 & 0.10 & 0.35 \\
\hline Dolomite (2) & 9 & 0.14 & 0.35 \\
\hline Gneiss (1) & 28 & 0.10 & 0.30 \\
\hline Gneiss (2) & 28 & 0.09 & 0.40 \\
\hline Granite (1) & 32 & 0.10 & 0.32 \\
\hline Granite (2) & 32 & 0.09 & 0.30 \\
\hline Granodiorite (1) & 29 & 0.15 & 0.25 \\
\hline Greywacke (1) & 18 & 0.08 & 0.22 \\
\hline Limestone (1) & 8 & 0.10 & 0.32 \\
\hline Limestone (2) & 8 & 0.12 & 0.33 \\
\hline Marble (1) & 9 & 0.15 & 0.30 \\
\hline Marble (2) & 9 & 0.17 & 0.40 \\
\hline Marl (1) & 7 & 0.12 & 0.32 \\
\hline Norite (1) & 20 & 0.10 & 0.32 \\
\hline Quartzite (1) & 20 & 0.10 & 0.32 \\
\hline Quartzite (2) & 20 & 0.08 & 0.22 \\
\hline Sandstone (1) & 17 & 0.05 & 0.40 \\
\hline Sandstone (2) & 17 & 0.08 & 0.46 \\
\hline Shale (1) & 7 & 0.05 & 0.31 \\
\hline Shale (2) & 7 & 0.03 & 0.18 \\
\hline Siltstone(1) & 7 & 0.13 & 0.35 \\
\hline Siltstone(2) & 7 & 0.09 & 0.23 \\
\hline Tuff (1) & 13 & 0.10 & 0.27 \\
\hline Schist (2) & 10 & 0.02 & 0.31 \\
\hline Gabbro (2) & 27 & 0.16 & 0.20 \\
\hline
\end{tabular}

As it was demonstrated previously and applied in this research, the rigidity of the rock $(R)$ is equal to the HoekBrown material constant $\left(m_{\mathrm{i}}\right)$, thus $R \approx m_{\mathrm{i}}$, [12] i.e.:

$v=\frac{1}{\sqrt{m_{\mathrm{i}}}+1}$. 


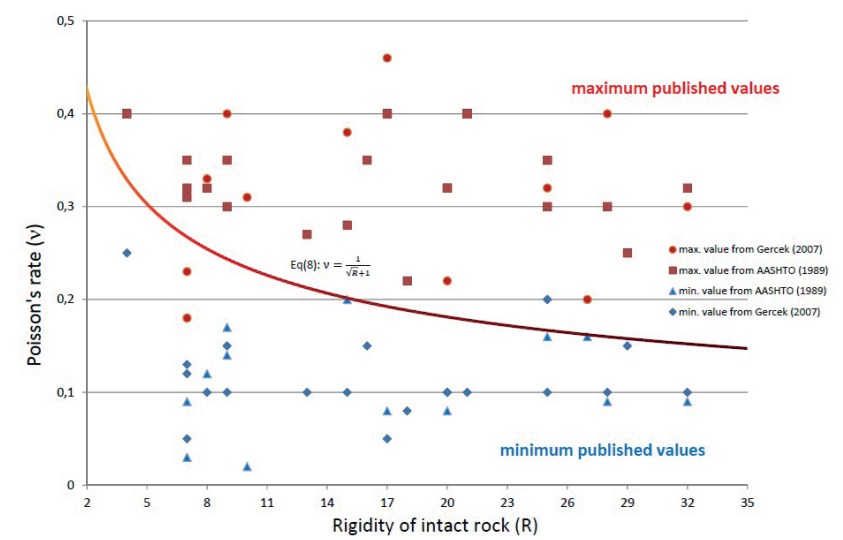

Fig. 6 Plotted maximum and minimum Poisson's rate $(v)$ of the intact rock in function of the rigidity $(R)$ - using the published values of Gercek [4] and AASHTO [7] using curve of Eq. (12), (14)

In Fig. 7 the predicted Poisson's ratio from Hoek-Brown constants were plotted in the function of the published Poisson's rate (the data were collected in Table 5). The published data usually near to the predicted data - the differences usually between \pm 0.05 , but except the shale and siltstone from [7] between \pm 0.1 line.

\section{Conclusions}

The goal of this theoretical research was to investigate how the Poisson's ratio of the intact rock relates to the rigidity of the material. According to the different theories the Poisson's ratio decreasing in case of increasing rigidity. Comparing the different equations and supposing that the rigidity of the rock is equal to the HoekBrown material constant $m_{\mathrm{i}}$, we received the best results using Eq. (17):

$$
v=\frac{1}{\sqrt{m_{\mathrm{i}}}+1} \text {. }
$$

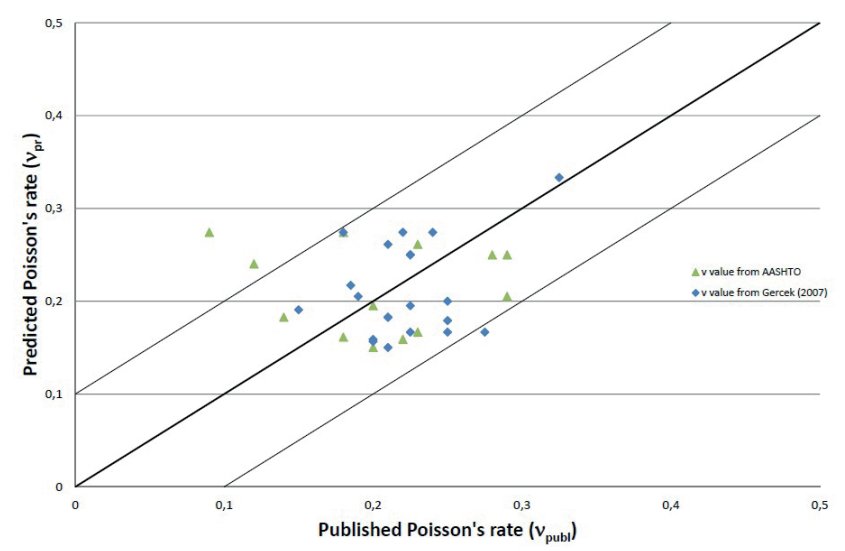

Fig. 7 Comparing the predicted Poisson's rate to the published Poisson's rate
Table 5 Comparison the calculated (predicted) Poisson's ratio to the published values

\begin{tabular}{|c|c|c|c|}
\hline \multirow{2}{*}{ Type of rock } & \multirow{2}{*}{$\begin{array}{c}\text { Predicted } \\
\text { Poisson's rate }\end{array}$} & \multicolumn{2}{|c|}{ Published Poisson's rate value (v) } \\
\hline & & Gercek [4] & AASHTO [7] \\
\hline Andesite & 0.17 & 0.28 & \\
\hline Basalt & 0.17 & 0.23 & 0.23 \\
\hline Claystone & 0.33 & 0.33 & \\
\hline Conglomerate & 0.18 & 0.25 & \\
\hline Diabase & 0.21 & 0.19 & \\
\hline Diorite & 0.17 & 0.25 & 0.29 \\
\hline Dolerite & 0.20 & 0.25 & \\
\hline Dolomite & 0.25 & 0.23 & 0.29 \\
\hline Gneiss & 0.16 & 0.20 & 0.22 \\
\hline Granite & 0.15 & 0.21 & 0.20 \\
\hline Granodiorite & 0.16 & 0.20 & \\
\hline Greywacke & 0.19 & 0.15 & \\
\hline Limestone & 0.26 & 0.21 & 0.23 \\
\hline Marble & 0.25 & 0.23 & 0.28 \\
\hline Marl & 0.27 & 0.22 & \\
\hline Norite & 0.18 & 0.21 & \\
\hline Quartzite & 0.18 & 0.21 & 0.14 \\
\hline Sandstone & 0.20 & 0.23 & 0.20 \\
\hline Shale & 0.27 & 0.18 & 0.09 \\
\hline Siltstone & 0.27 & 0.24 & 0.18 \\
\hline Tuff & 0.22 & 0.19 & \\
\hline Schist & 0.24 & & 0.12 \\
\hline Gabbro & 0.16 & & 0.18 \\
\hline
\end{tabular}

As it is well-known, the Hoek-Brown constant depend on many things, e.g. water content (see e.g. [18] or heating cycles [19], among the others. Recently, Vásárhelyi et al. [20] analyzed the Hoek-Brown equation and suggested minor modification of it for Hungarian granitic rocks.

According to the publication of [8], in the rock engineering practice, the knowledge of the Poisson's rate value of the rock mass is highly important. The Poisson's rate value highly depend on the quality of the rock mass, thus in the increasing if the Geological Strength Index (GSI) increasing $[8,21]$ :

$v_{\mathrm{rm}}=-0.002 \mathrm{GSI}+v_{\mathrm{i}}+0.2$.

Where $v_{\mathrm{rm}}$ and $v_{\mathrm{i}}$ is the Poisson's ratio of the rock mass and the intact rock, respectively, and GSI is the Geological Strength Index.

Aydan et al. [22] also investigated the influence of the rock mass quality for the Poisson's ratio. They found the following relation between the ratio of the Poisson's ratio 
of rock mass $\left(v_{\mathrm{rm}}\right)$ and intact rock $\left(v_{\mathrm{i}}\right)$, in the function of Rock Mass Rate (RMR):

$$
\frac{v_{\mathrm{rm}}}{v_{\mathrm{i}}}=0.5-0.2 \frac{\mathrm{RMR}}{\mathrm{RMR}+0.2(100-\mathrm{RMR})} .
$$

Using Eq. (17) the connection between the rock mass quality and the Poisson's ratio of the rock mass $\left(v_{\mathrm{rm}}\right)$ can be calculating more precisely.

We know well, that Poisson ratio is a composition parameter. A better material characterization can be achieved by the theoretical established Lamé coefficients, the isotropic invariants of the elastic material. This is rather apparent considering the time dependence of the laboratory experiments (see [23] and Fig. 8).

The rheological properties of rocks are universal [24] and may not be neglectable at the standardized laboratory time scales and that could be the reason of the observed uncertainty of the data.

\section{References}

[1] Ulusay, R., Hudson, J. A. "The Complete ISRM Suggested Methods for Rock Characterization, Testing and Monitoring: 1974-2006", ISRM Turkish National Group, Ankara, Turkey, 2007.

[2] Kumar, J. "The effect of Poisson's ratio on rock properties", In: SPE Annual Fall Technical Conference and Exhibition, New Orleans, USA, 1976, pp. 1-12. https://doi.org/10.2118/6094-MS

[3] Aydan, Ö., Akagi, T., Kawamoto, T. "The squeezing potential of rocks around tunnels; Theory and prediction", Rock Mechanics and Rock Engineering, 26(2), pp. 137-163, 1993. https://doi.org/10.1007/BF01023620

[4] Gercek, H. "Poisson's ratio values for rocks", International Journal of Rock Mechanics and Mining Sciences, 44(1), pp. 1-13, 2007. https://doi.org/10.1016/j.ijrmms.2006.04.011

[5] Davarpanah, M., Somodi, G., Kovács, L., Vásárhelyi, B. "Complex analysis of uniaxial compressive tests of the Mórágy granitic rock formation (Hungary)", Studia Geotechnica et Mechanica, 41(1), pp. 21-32, 2019

https://doi.org/10.2478/sgem-2019-0010

[6] Walsh, J. B. "The effect of cracks in rocks on Poisson's ratio", Journal of Geophysical Research, 70(20), pp. 5249-5257, 1965. https://doi.org/10.1029/JZ070i020p05249

[7] American Association of State Highway and Transportation Officials "Standard Specifications for Highway Bridges", 14th ed., AASHTO, Washington DC, USA, 1989.

[8] Vásárhelyi, B. "A possible method for estimating the Poisson's rate values of the rock masses", Acta Geodaetica et Geophysica Hungarica, 44(3), pp. 313-322, 2009.

https://doi.org/10.1556/AGeod.44.2009.3.4

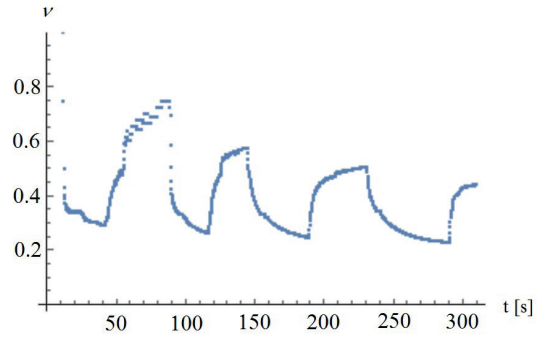

Fig. 8. Poisson's rate in the function of time in case of cycle loading experimental results [23]

\section{Acknowledgement}

The project presented in this article is supported by National Research, Development and Innovation Office - NKFIH 124366 and NKFIH 124508 and the Hungarian-French Scientific Research Grant (No. 2018-2.1.13-TÉT-FR-2018-00012).

[9] Kumar, R., Bhargava, K., Choudhury, D. "Correlations of Uniaxial Compressive Strength of Rock Mass with Conventional Strength Properties through Random Number Generation", International Journal of Geomechanics, 17(2), 2017. https://doi.org/10.1061/(ASCE)GM.1943-5622.0000716

[10] Andreev, G. E. "Brittle failure of rock mechanics", Balkema, Rotterdam, The Netherlands, 1995.

[11] Barton, N. "The shear strength of rock and rock joints", International Journal of Rock Mechanics and Mining Sciences \& Geomechanics Abstracts, 13(9), pp. 255-279, 1976. https://doi.org/10.1016/0148-9062(76)90003-6

[12] Cai, M. "Practical estimates of tensile strength and Hoek-Brown strength parameter $m_{\mathrm{i}}$ of brittle rocks", Rock Mechanics and Rock Engineering, 43(2), pp. 167-184, 2010. https://doi.org/10.1007/s00603-009-0053-1

[13] Hoek, E., Brown, E. T. "Underground excavation in rock", Institution of Mining and Metallurgy, London, UK, 1980.

[14] Hoek, E., Brown, E. T. "The Hoek-Brown failure criterion and GSI - 2018 edition", Journal of Rock Mechanics and Geotechnical Engineering, 11(3), pp. 445-463, 2019. https://doi.org/10.1016/j.jrmge.2018.08.001

[15] Hoek, E. "Practical rock engineering", 2007. [online] Available at: http://www.rocscience.com [Accessed: 06 September 2019]

[16] Zhang, N., Sheng, Z., Li, X., Li, S., He, J. "Study of relationship between Poisson's ratio and angle of internal friction for rocks", Chinese Journal of Rock Mechanics and Engineering, 30(Supl.1), pp. 2599-2609, 2011. (in Chinese).

[17] Stagg, K. G., Zienkiewicz, O. C. "Rock mechanics in engineering practice", Wiley, London, UK, 1968. 
[18] Vásárhelyi, B., Davarpanah, M. "Influence of Water Content on the Mechanical Parameters of the Intact Rock and Rock Mass", Periodica Polytechnica Civil Engineering, 62(4), pp. 1050-1066, 2018.

https://doi.org/10.3311/PPci.12173

[19] Török, Á., Vásárhelyi, B. "Rigidity of sandstone at elevated temperatures", In: Ulusey (ed.) Rock Mechanics and Rock Engineering: From the Past to the Future, Taylor \& Francis Group, London, UK, 2016, pp. 345-348.

[20] Vásárhelyi, B., Kovács, L., Török, Á. "Analysing the modified Hoek-Brown failure criteria using Hungarian granatic rocks", Geomechanics and Geophysics for Geo-Energy and Geo-Resources, 2(2), pp. 131-136, 2016. https://doi.org/10.1007/s40948-016-0021-7

[21] Vásárhelyi, B., Kovács, D. "Empirical methods of calculating the mechanical properties of the rock mass", Periodica Polytechnica Civil Engineering, 61(1), pp. 39-50. 2017.

https://doi.org/10.3311/PPci.10095
[22] Aydan, Ö, Tokashiki, N., Genis, M. "Some considerations on yield (failure) criteria in rock mechanics", In: 46th US Rock Mechanics/ Geomechanics Symposium, Chicago, Illinois, USA, 2012, Document ID: ARMA 12-640.

[23] Ván, P., Lökös S., Polyák, Z., Kovács, L. "A gyöngyösoroszi andezit reológiai tulajdonságai" (Rheological properties of the andesite from Gyöngyösoroszi), In: Mérnökgeológia-Közetmechanika 2018 (Engineering Geology - Rock Mechanics 2018), 2018, pp. 237-246. (in Hungarian)

[24] Asszonyi, Cs., Fülöp, T., Ván, P. "Distinguished rheological models for solids in the framework of a thermodynamical internal variable theory", Continuum Mechanics and Thermodynamics, 27(6), pp. 971-986, 2015,

https://doi.org/10.1007/s00161-014-0392-3 